\title{
Au-Zn (Gold-Zinc)
}

H. Okamoto

The Au-Zn phase diagram in [Massalski2] was redrawn from [1989Oka]. [2003Liu] assessed the Au-Zn system based on data given in [19890ka] and more recent data reported by [1988Ips] and [1993Pra]. The result is shown in Fig. 1. The diagrams of [19890ka] and [2003Liu] are different in detail. Experimental work may be needed to clarify the disagreement.

\section{References}

1988Ips: H. Ipser and R. Krachler, The Au-Zn Melting Diagram in the Range of the $\beta^{\prime}-A u Z n$ Phase, Scr. Metall., 1988, 22, p 1651-1654
1989Oka: H. Okamoto and T.B. Massalski, The Au-Zn (GoldZinc) System, Bull. Alloy Phase Diagrams, 1989, 10(1), p 59-69

1993Pra: R. Prasad, M. Bienzie, and F. Sommer, Thermodynamics of Gold-Rich Au-Zn Alloys, J. Alloys Compd., 1993, 200, p 69-74

2003Liu: H.S. Liu, K. Ishida, Z.P. Jin, and Y. Du, Thermodynamic Assessment of the Au-Zn System, Intermetallics, 2003, 11(10), p 987-994

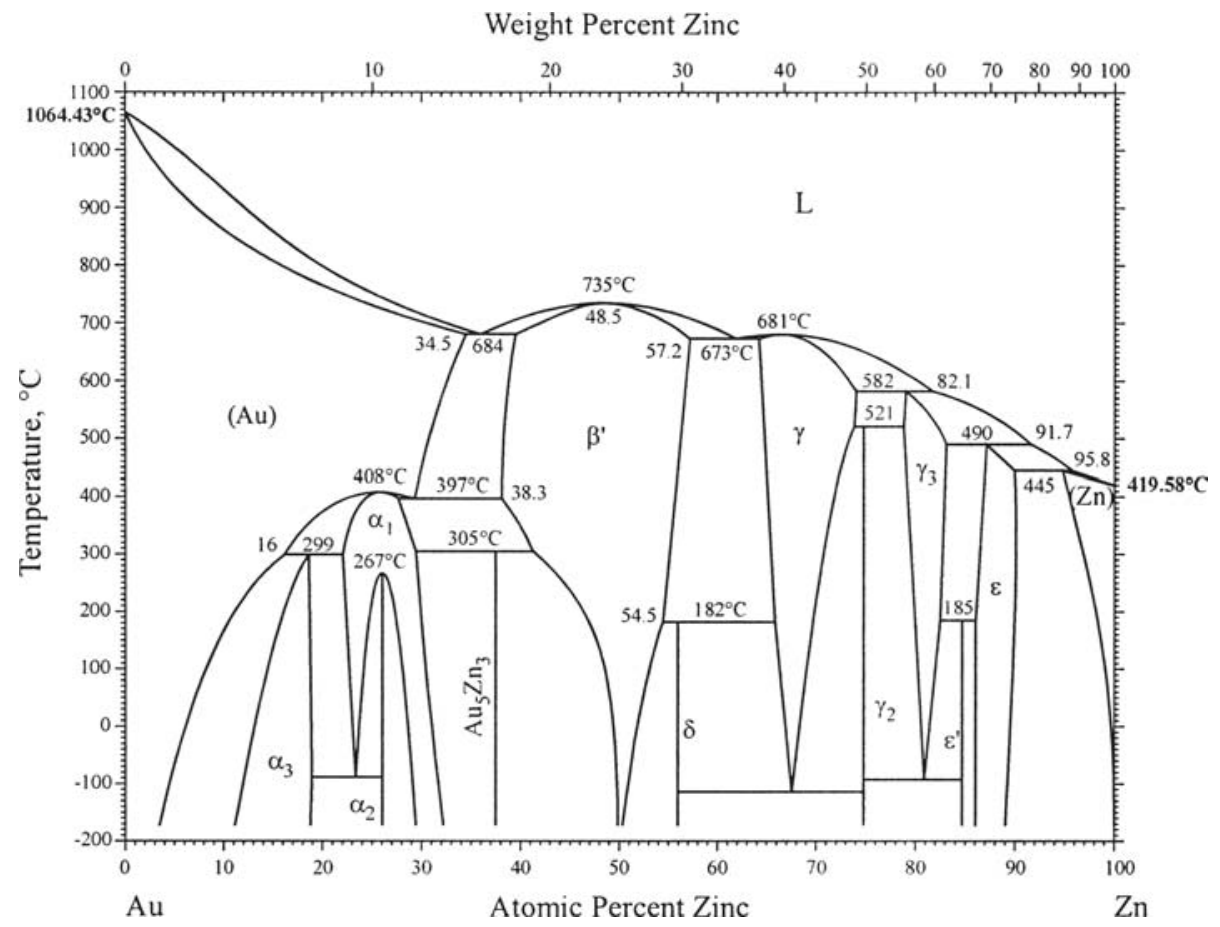

Fig. $1 \mathrm{Au}-\mathrm{Zn}$ phase diagram 